\title{
The Main Method of Digital Mine Map
}

\author{
Lingling HAN \\ Hebei Energy College of Vocation and Technology \\ Tangshan Hebei \\ China 063000 \\ Email:hanlingling2002@126.com
}

\begin{abstract}
-mining map digitizing of various types of coal mining map digitizing processing new technology, is to establish a modern mine enterprise's essential condition and basic construction. Around the mine map digitization concept, put forward five kinds of digital mine map method and its application conditions, for all types of mining enterprises in accordance with the actual conditions of use.
\end{abstract}

\section{Key words-mine map; digital engineering; design; CAD}

In the coal production of our country, most design of coal mine and mining are still need to be completed by using the traditional manual drawing method, it not only has low efficiency, high cost, but also affects the establishment of information and digital business process.

I. the main problems in the traditional map processing

The traditional mine map processing and mining design work need to complete by lots of people, so the main problems are: (1) design of drawing has a slow speed and long cycle; (2)workload of the repeat drawing is heavy. The partial drawings of the coal mine production or the drawings of most of the contents are repeatable, in each drawing the repetitive content should be redrawn, so it wastes a lot of manpower and man-hour; (3) the quality of the drawing paper is bad, standardization degree is low; (4) the drawings have low precision. Drawings of manual design generally have low precision and errors, some errors will bring the serious production problem; (5)utilization rate of the drawings is low , it is not easy to preserve, communication and management; 6) the high cost, low efficiency and poor benefit .

\section{II. definitions of mining map digitizing and software environment}

\section{A definitions of mining map digitizing}

Digitizing mining map refers to the use of manual input, image scanning, digital instrument, automatic drawing, direct drawing to vector mine map, it can be used as digital files by using computer to draw, edit, modify, preserve, output, and exchange .

\section{$B \quad$ The software environment of mining map digitizing}

The choice of Mining map of digitizing software platform is crucial, it must meet 3 basic requirements: (1) powerful function of drawing, editing, modifying; (2) the operation is simple, easy to learn and use; (3)the price is cheap. Autodesk company, an American company, one of its software----AutuCAD2000 software which has powerful function of drawing, editing and modifying, it can meet a variety of complex requirements of drawing vectorization . Another choice is to choose the domestic development of measuring system software and bind with AutoCAD,

due to the general measurement system lack modifying function, its application is more complex, graphics file format has poor compatibility, and high price, so measuring system graphics must go to AutoCAD for editing and drawing [1].

\section{The main methods of digitizing}

\section{A manual input}

Manual input coordinates will make the mining map digitize, it means in the mine map the quantity of equivalent characteristic point coordinate (x,y) will be marked by using delta plate, scale, a protractor, then drawing commands will be selected in AutoCAD, Coordinate value will be input in the command line to draw. This method requires measuring and drawing should work at the same time, it means a point should be taken in the drawing map, and then AutoCAD draw a point. This mode is suitable for the drawings which have less content, simple lines, small map, or drawings with dimensions of construction plan. For beginners, it is a very good practice for CAD drawing skills; they can learn many skills and methods [2].

\section{$B$ digitalization of scanning image}

For the digitalization of Mine map scanning image, it means the mine map is scanned into dot raster image by the large engineering scanner, then inserted into AutoCAD, the image will be adjusted to the proper proportion and position by scaling, rotating, cutting and editing, in the final image, the map content is drawn into vector graphics. This digital method of mine map has the quality of being fast, low cost, and high precision, it is applicable to all kinds of mine map. Especially for those irregular complex mine map, it is the most economic and fast processing method.

\section{$C \quad$ digitalization of the mine map drawings by digitizer}

If you want to use the digitizer to digitalize the mine map drawings, you must purchase special digital equipment and corresponding configuration to the driver. Digitizer is an absolute pointing device.” Absolute" means every point of the digital instrument and the specific location on the graph must correspond with each other, which makes the digital instrument to be the most useful digital graphics tools in AutoCAD. Digital instrument can be calibrated or configured.

When digitalizing graphics, you should calibrate digital instrument firstly, that is to coordinates the digitizer and drawing graphics alignment. If the drawings are too big, digitizer can't hold, you can separate graphics into several 
parts to input, but you have to ensure alignment of each part. Digitalization of the mine map drawings by digitizer is actually to input drawing points in the map then calculate the selected set of points, finally to fit and draw the graphics object by different ways. This method is suitable for all kinds of mine map digitization, it is economic and applicable, but need people's closely coordination, and relatively slow speed

\section{D programming drawing}

programming drawing is the automatic drawing program with computer language programming, after the original data are input computer, automatic drawing will be formed. Because the coal mine map is a kind of complicated engineering maps, map content is complex and time-varying, it's difficult to use programming method to draw, for the stable engineering standards, and automatic programming can be used.

Software development language of programming include AutoCAD and Auto LISP language, you can also use C, VB, Delphi.

Some mine ground measurement system which is based on borehole and measuring point coordinate automatic mapping system, but the system has low function to identify and treat the boundary conditions, and it isn't applicable for complex geological conditions, it can only be used for simple condition of mine. Programming automatic drawing method is simple, but development of the special software is difficult, high costly and expensive, the cost of the early development and purchase is 20 - 300000 Yuan. The recommended method is to build gallery included original mine drawings, when the drawings are used, they are called according to the similar condition, finally according to the actual conditions, and partial modification will be made.

\section{E mining design $C A D$}

Design of coal mining is the regular work, design covers all aspects of production mine. Mining design includes: (1) design, such as the development of plan design and other design; (2)the professional design, such as the ventilation system, transport, electrical and mechanical design; (3) engineering design, such as the construction and design of bottom, roadway, intersection, copper chamber. These three designs need to use AutoCAD directly, but the drawing techniques and methods vary.

\section{1) Program design}

Design of mining is mainly on the contour map, in another words, planar graph is formed by arranging a mine tunnel contour diagram layout, chamber, surface mining, coal pillar boundary line, line on the contour map. Profile is drawn according to the drilling data, the comprehensive geological data, and based on histogram, a planar graph contour according to a survey line or artificially imposed section of line, and added with the roadway and other content. That is to say, the main steps of these kinds of drawing mine map are: according to the design draw the suitable proportion of the contour map, according to a profile contour drawing, final layout design. This kind of mine map includes: various kinds of mine flat, profile map.

\section{2) professional design}

This kind of ore drawing ventilation system has circuit diagram of hydrological geology, underground transport system, underground power supply system, drainage system, mechanical and electrical equipment layout, piping arrangement system, communication system, safe escape. These drawings is characterized in mine basic drawings on the basis of the corresponding increase professional primitives and reduce or omit basic drawing in excess and the formation of special drawing.

This drawing is relatively simple, based on the original image you can modify into a graph by increasing and deleting content, but you need to create the special library.

\section{3) Construction design}

Mine construction mainly includes the bottom line layout, roadway sections, cross point construction drawing, copper room construction plans. This kind of ore drawing must be accurately plotted rules construction plan according to the sizes; it should have accurate size, content complete, detailed description and the comprehensive marking, etc. This kind of design is generally in proportion to 1:1 design; it requires calculation, measurement, and draw at the same time. After the design is completed, the map will zoom into the map scale, then the dimension, add text, and finally print out the charts.

Computer aid design and drawing make the speed of graphs much faster than manual drawing, can save time and effort over $2 / 3$ [4]

\section{IV. conclusions}

mine map has professional characteristics, such as variety, complexity, changeful, strong repeatability. Mining map digitizing is much more complicated than other industry; we should adopt comprehensive digital processing technology, according to different types of the drawings, the reasonable method for digitizing method should be chosen. There are mainly 5 kinds: (1) manual input; (2)the image scanning; (3) digitizer; (4) programming drawing; (5)the mining design CAD. One of the fastest and most economic methods is the image scanning, mining design need to purchase or develop mining standard library.

New technology of mining map digitizing solve the traditional ore drawing and mining design problems, it's the basic construction of mining enterprises to establish digital resources and application system. We must make greater efforts to promote the application of this new technology. Mining map digitizing software platform choice is crucial, we must be careful.

\section{References}

[1] Wang Jianxue, Yang Bensheng, Wu Meiliang. Mining map digitizing and main methods Coal science and technology 2004, 32 ( 5)

[2] Yang Hongmin; Yang Zhen; Lv Qinggang In Coal Mine Based on AutoCAD stereo drawing 2003 ( 03)

[3] Zhang Ruixin A new virtual reality technology and its application in mining engineering 1998 ( 03)

[4] Chen Xu; Zhang Jianping; Zhang Li; Based on GIS and VR mining map digitizing [ study ] - Journal of Taiyuan University of Technology 2003 (02) 